\title{
INVERSÃO DA SACAROSE UTILIZANDO ÁCIDO CÍTRICO E SUCO DE LIMÃO PARA PREPARO DE DIETA ENERGÉTICA DE Apis mellifera LINNAEUS, 1758
}

\author{
Inversion of the sucrose using citric acid and lemon juice for \\ preparing energetic diet of Apis mellifera Linnaeus, 1758 \\ Deodoro Magno Brighenti ${ }^{1}$, César Freire Carvalho ${ }^{2}$, \\ Carla Regina Guimarães Brighenti ${ }^{3}$, Stephan Malfitano Carvalho ${ }^{2}$
}

\begin{abstract}
RESUMO
Em época de escassez de néctar, pode-se fornecer ao enxame uma suplementação alimentar utilizando "açúcar invertido" que é obtido pela hidrólise da sacarose em meio ácido por aquecimento, formando uma mistura de glicose e frutose. O ácido normalmente utilizado em tal reação é o ácido cítrico, no entanto, diante da dificuldade de pequenos produtores apícolas em obterem tal produto comercialmente, uma alternativa seria substituí-lo pela utilização de suco de limões. Sendo assim, o objetivo deste trabalho foi quantificar a inversão da sacarose em dietas para operárias de Apis mellifera, empregando-se o ácido cítrico e sucos de limões. Prepararam-se 21 soluções aquosas de açúcar cristal na proporção de $100 \mathrm{~g} / 100 \mathrm{~mL}$, colocando-se em cada uma 1,0; 2,0; 3,0; 5,0; 10,0; 15,0 ou 20,0 mL de suco dos limões Galego [Citrus aurantifolia (C.) Swingle], Tahiti [Citrus latifolia Tanaka] ou Cravo [Citrus limonia (L.) Osbeck]. Além dessas, outras seis soluções aquosas de açúcar na mesma proporção foram preparadas adicionando-se 0,$1 ; 0,16 ; 0,3$; 0,5 e 0,7 g de ácido cítrico e uma para testemunha. Quantificou-se a inversão pelo método de Somogyi-Nelson. Para o limão Cravo foi encontrada a menor porcentagem de inversão. Em relação a adição de ácido cítrico, constatou-se que ao colocar $0,1 \mathrm{~g}$, a inversão foi estimada em 12,2\% enquanto que, com a adição de $0,16 \mathrm{~g}$, a inversão seria de 18,8\%. A quantidade máxima de ácido cítrico a ser adicionada foi estimada em $0,18 \mathrm{~g}$ adotando como critério o pH médio de 3,3 dos méis de abelhas africanizadas. Para os sucos dos limões Galego, Tahiti e Cravo, quando utilizados como substitutos do ácido cítrico, estimou-se a quantidade máxima a ser adicionada sendo igual a 2,1; 3,6 e 5,3 mL, respectivamente, para cada $100 \mathrm{~g}$ de açúcar em $100 \mathrm{~mL}$ de água, para o pH fixado em 3,3. Considerandose a inversão e o pH, o suco do limão Tahiti forneceu melhores resultados.
\end{abstract}

Termos para indexação: Citrus, açúcar, abelha, alimentação.

\begin{abstract}
In times of nectar shortage, food supplementation using "inverted sugar" obtained by sucrose hydrolysis in an acid environment by heating can be supplied to the hive, forming a glucose and fructose mixture. The acid usually used in such a reaction is the citric acid, however, due to the difficulty that small producers have to obtain the product commercially, an alternative would be to replace it with lemon juice. The objective of this work was to quantify the inversion of sucrose present in Apis mellifera worker diets by employing commercial citric acid and lemon juice. A total of 21 aqueous solutions of granulated sugar at the proportion of $100 \mathrm{~g} / 100 \mathrm{~mL}$ were prepared, placing in each one $1.0 ; 2.0 ; 3.0 ; 5.0 ; 10.0 ; 15.0$ or $20.0 \mathrm{~mL}$ of the juices of the Galego [Citrus aurantifolia (C.) Swingle], Tahiti [Citrus latifolia Tanaka] or Cravo [Citrus limonia (L.) Osbeck] lemon varieties. In addition to those, six other aqueous sucrose solutions were prepared by adding 0.0 (control); $0.16 ; 0.3 ; 0.5$ and $0.7 \mathrm{~g}$ citric acid. Sucrose inversion was quantified by using the Somogyi-Nelson method. For the Cravo lemon, the lowest inversion rate was found. Regarding the addition of citric acid, it was estimated that in placing $0.1 \mathrm{~g}$, the inversion was of $12.2 \%$ while with $0.16 \mathrm{~g}$, an inversion of $18.8 \%$ sucrose present in the solution. The maximum amount of citric acid to be added was estimated to be $0.18 \mathrm{~g}$, adopting as a criterion the mean $\mathrm{pH}$ of 3.3 in Africanized bee honey. If Galego, Tahiti and Cravo lemon juices are used as replacements for the citric acid, the maximum added amount should be $2.1,3.6$ and $5.3 \mathrm{~mL}$, respectively, for each $100 \mathrm{~g}$ sugar $/ 100 \mathrm{~mL}$ water, at fixed $\mathrm{pH}$ of 3.3. Considering the inversion rate and $\mathrm{pH}$ level recommended for the use of citric acid, Tahiti lemon juice provides better results.
\end{abstract}

Index terms: Citrus, sugar, bee, food.

(Recebido em 16 de março de 2009 e aprovado em 21 de maio de 2010)

\section{INTRODUÇÃO}

Sob condições naturais, a fonte de alimento energético utilizada pelas abelhas é o néctar oriundo de espécies vegetais. As concentrações de açúcares encontradas nesses néctares variam de 5 a $80 \%$ (White Júnior, 1979; Herbert Júnior, 1992; Schmidt et al., 1995).

\footnotetext{
1Universidade Federal de Lavras/UFLA - Cx. P. 3037 - 37200-000 - Lavras, MG - deodorobrighenti@gmail.com

2Universidade Federal de Lavras/UFLA - Departamento de Entomologia/DEN - Lavras, MG

${ }^{3}$ Universidade Federal de São João Del-Rei/UFSJ - Departamento de Engenharia de Biossistemas/DEPEB - São João Del-Rei, MG
} 
Em período de escassez de néctar e também dependendo do tipo de exploração apícola, como, por exemplo, produção de própolis, é comum a suplementação alimentar dos enxames, empregando-se solução aquosa de sacarose a 50\%. Normalmente, a abelha não utiliza a sacarose diretamente para sua alimentação sem que ocorra sua inversão, mesmo que parcial. Durante esse processo, as abelhas produzem por meio das glândulas hipofaringeanas as enzimas diástase, glicose oxidase e invertase, que transformam os açúcares de cadeia mais longa em monossacarídeos (Winston, 1987). Nesse procedimento metabólico, há consumo de energia pelas abelhas, possivelmente reduzindo a longevidade desses insetos, situação que é indesejável para manutenção de enxames com alta densidade populacional (Barker \& Lehner, 1978).

Para o fornecimento de uma dieta aos adultos de abelhas Apis mellifera Linnaeus, 1758 que contém sacarose, pode-se utilizar o "açúcar invertido" o qual pode ser obtido por meio da hidrólise ácida e aquecimento, resultando em uma mistura de glicose e frutose. Esse desdobramento também pode ser obtido quando a sacarose é catalisada pela enzima invertase ( $\beta$-fructofuranosidase), contudo, nesse último processo e em relação ao primeiro, o fator limitante é o alto custo dessa enzima (Rodrigues et al., 2000).

O nome de "açúcar invertido" se origina pelo fato de que a reação inverte o plano de luz polarizada na direção oposta da sacarose. A sacarose desvia a luz polarizada à direita $\left(+66^{\circ}\right)$, enquanto a frutose desvia à esquerda $\left(-92^{\circ}\right)$ e a glicose à direita $\left(+52^{\circ}\right)$, com isso o açúcar invertido desvia o plano da luz à esquerda devido à natureza levógira da frutose (Guy et al., 1992).

De acordo com Lengler et al. (2000), pode-se preparar o açúcar invertido utilizando-se $1000 \mathrm{~g}$ de açúcar cristal acrescido de $1,0 \mathrm{~g}$ de ácido cítrico e $1000 \mathrm{~mL}$ de água. De forma semelhante, Pereira et al. (2006) sugeriram quantidades equivalentes de açúcar e água, contudo empregando-se 1,6 g de ácido cítrico. Esse ácido pode ser obtido comercialmente ou por meio do suco de limão, cujo teor médio é da ordem de 6,0\% (Holme \& Peck, 1998).

Assim, considerando a escassez de informações sobre a utilização do suco de limão como uma alternativa ao emprego de produtos químicos sintéticos para inversão da sacarose do açúcar cristal comercial, objetivou-se, neste trabalho, avaliar o efeito da utilização de ácido cítrico e suco dos limões Galego, Tahiti e Cravo na inversão da sacarose para preparo de dieta artificial para adultos de A. mellifera.

\section{MATERIAL E MÉTODOS}

Foram preparadas 27 soluções utilizando-se $100 \mathrm{~g}$ do açúcar cristal comercial diluídos em $100 \mathrm{~mL}$ de água, obtendose volume final de $164 \mathrm{~mL}$ em cada solução. Empregou-se, para inversão da sacarose, o ácido cítrico ou suco de limão, representando os tratamentos. $\mathrm{O}$ ácido cítrico foi utilizado nas quantidades de 0,$1 ; 0,16 ; 0,3 ; 0,5$ ou $0,7 \mathrm{~g}$ do produto comercial ( $\mathrm{pH} 1,85)$, para cada solução preparada, sendo a quantidade de 0,16 determinada pela proporção utilizada por Pereira et al. (2006). Utilizou-se também sucos dos limões Galego [Citrus aurantifolia (C.) Swingle], Tahiti [Citrus latifolia Tanaka] e Cravo [Citrus limonia (L.) Osbeck], adicionando-se 1,0;2,0; 3,0; 5,0; 10,0; 15,0 e 20,0 mL em cada uma das soluções aquosas de açúcar cristal para realização da hidrólise ácida. Como testemunha, empregou-se uma solução isenta de ácido cítrico e suco de limão.

Os frutos foram coletados no pomar de fruticultura da UFLA. Seguindo recomendações de Gayet et al. (1995), para obtenção de frutos com maior concentração de ácido, foram colhidos frutos com tamanho variando de 25 a $42 \mathrm{~mm}$ de diâmetro e com superfície de casca lisa e coloração verde do limão Galego, para o Tahiti baseou-se no tamanho de 45 a $65 \mathrm{~mm}$, de casca lisa e verde brilhante. Já para o fruto do limão Cravo a seleção foi determinada pelo tamanho entre 33 a $62 \mathrm{~mm}$, com coloração da casca verde e textura rugosa.

Foram medidos o potencial hidrogeniônico $(\mathrm{pH})$, açúcares totais, redutores e não-redutores e a acidez titulável (AT) de cada suco de limão utilizado, sendo realizadas duas medições em cada solução. Como testemunha, foi usada uma solução aquosa de açúcar cristal (1:1).

Posteriormente, cada solução foi colocada em um Becker de $200 \mathrm{~mL}$ e submetida ao aquecimento até ebulição e em seguida colocada para resfriamento em temperatura ambiente, ressaltando que o tempo necessário para ocorrência da ebulição variou de acordo com a solução. Os teores de açúcares redutores (monossacarídeos) e totais foram identificados pelo método de Somogyi modificado por Nelson (1944), em que o açúcar é aquecido com uma solução alcalina de tartarato de arsênio, produzindo um composto de coloração azul quantificado por espectrofotometria a $510 \mathrm{~nm}$ (Guy et al., 1992; Silva et al., 2003). Por meio da diferença entre esses resultados, foi possível a obtenção dos teores de açúcares não-redutores (dissacarídeos). A porcentagem de inversão da sacarose foi obtida por meio da dosagem da sacarose, glicose e frutose, utilizando-se a equação (Rodrigues et al., 2000):

$\%$ inversão $=\frac{\text { açúcares redutores }}{\text { açúcares redutores }+1,05 \text { açúcares não-redutores }} \times 100$ 
Para critério de recomendação de limites inferior e superior da adição de ácido cítrico ou suco de limão, foi utilizado o intervalo de $\mathrm{pH}$ de méis citado por Marchini et al. (2004) e Moreti et al. (2009), visando a obtenção de uma dieta energética, para suplementação alimentar, com pH próximo àquele normalmente ingerido pelas abelhas africanizadas. Foi medido também o pH de amostras de méis obtidas, mensalmente, no apiário da UFLA no período de julho de 2007 a junho de 2008.

Considerando a natureza quantitativa dos dados obtidos, esses foram submetidos à análise de regressão polinomial.

\section{RESULTADOS E DISCUSSÃO}

Ao se avaliarem os resultados das análises laboratoriais obtidas para os sucos dos limões, verificouse que os valores de $\mathrm{pH}$ variaram de 1,94 no limão Galego a 2,35 no limão Cravo (Tabela 1). Quanto ao teor de ácido cítrico, o qual é um fator importante para desdobramento da sacarose, verificou-se que esse variou de um mínimo de 5,4\% no limão Cravo a 8,73\% no limão Galego. Esses resultados encontram-se dentro da acidez relatada por Holme \& Peck (1998) para limões, que é da ordem de 6,0\%.

Para os açúcares totais, redutores e não-redutores, os resultados também evidenciaram que os maiores teores foram encontrados no suco do limão Cravo, indicando ser esse o que possui maior conteúdo de sacarose.

Quando se analisou o açúcar cristal comercial, foi detectado que o $\mathrm{pH}$ é 6,72; os teores em porcentagem de açúcares totais, açúcares redutores e não-redutores foram de 80,10; 0,26 e 75,86\%, respectivamente.

Em relação à inversão da sacarose empregando-se os sucos de limões, constatou-se, de uma maneira geral e independente da espécie de limão, que ao se aumentar a quantidade empregada, há uma maior porcentagem de inversão. Ao se analisarem as inversões obtidas quando da utilização dos sucos de limões Galego e Tahiti, verificou- se que ambos comportaram-se de forma semelhante, sendo que as porcentagens de hidrólise variaram de uma média de 5,6\% ao se usar $1 \mathrm{~mL}$ de suco até um máximo de 53,7\% quando da utilização de $20 \mathrm{~mL}$ de suco do limão. Ao ser utilizado suco de limão Cravo, as porcentagens de inversão obtidas foram sempre inferiores aos demais sucos (Tabela 2). Usando-se a maior quantidade de suco de limões Galego e Tahiti, obteve-se mais de $50 \%$ de inversão, enquanto que, com a mesma quantidade de limão Cravo, obteve-se aproximadamente $35 \%$ de inversão.

Quanto ao teor de ácido cítrico encontrado nos sucos dos três limões o maior foi obtido para o Galego e o menor foi aquele encontrado no suco do limão Cravo, no entanto deve-se ressaltar que no suco de limão Cravo, foi obtida a maior concentração de açúcares totais e também não-redutores, o que pode influenciar no seu rendimento em relação aos demais limões. Em relação ao pH, aqueles mais ácidos foram os dois primeiros (Tabela 1). Essas características, possivelmente, foram as responsáveis pela menor porcentagem de inversão da sacarose no limão Cravo (Tabela 2).

Outro fator importante refere-se ao $\mathrm{pH}$ final da solução. À medida que se aumenta a quantidade de suco ou ácido cítrico na solução, observa-se uma redução desse fator, aumentando a acidez da solução, o que poderia causar rejeição do alimento por parte das abelhas (Tabelas 2 e 3).

Empregando-se sucos dos limões Galego e Tahiti, obteveram-se níveis de inversão crescentes, conforme o aumento da quantidade de suco empregada, mostrandose como uma alternativa natural à utilização do ácido cítrico quando se deseja obter esse desdobramento. No entanto, a adição de maiores quantidades de suco de limão, para melhorar a porcentagem de inversão, não é apropriada devido ao abaixamento do $\mathrm{pH}$, aumentando em demasia a acidez da solução e à possível elevação do custo final do alimento artificial a ser preparado, quando se considera a possibilidade de utilização por apicultores de pequeno porte em condições de campo.

Tabela 1 - Potencial hidrogeniônico $(\mathrm{pH})$, porcentagens de ácido cítrico, açúcares totais, redutores e não-redutores dos sucos de limões Galego, Tahiti ou Cravo.

\begin{tabular}{|c|c|c|c|c|}
\hline \multirow[b]{2}{*}{ Parâmetros avaliados } & \multicolumn{3}{|c|}{ Limões } & \multirow[b]{2}{*}{ Média } \\
\hline & $\begin{array}{c}\text { Galego } \\
\text { Citrus aurantifolia }\end{array}$ & $\begin{array}{c}\text { Tahiti } \\
\text { Citrus latifolia }\end{array}$ & $\begin{array}{c}\text { Cravo } \\
\text { Citrus limonia }\end{array}$ & \\
\hline $\mathrm{pH}$ & 1,94 & 2,23 & 2,35 & 2,17 \\
\hline Ácido cítrico (\%) & 8,73 & 6,19 & 5,40 & 6,77 \\
\hline Açúcares totais (\%) & 3,72 & 4,52 & 5,57 & 4,60 \\
\hline Açúcares redutores (\%) & 2,07 & 3,03 & 3,42 & 2,84 \\
\hline Açúcares não-redutores (\%) & 1,57 & 1,42 & 2,04 & 1,68 \\
\hline
\end{tabular}


Tabela 2 - Porcentagem da sacarose invertida (açúcar redutor - AR) e pH das soluções de açúcar cristal submetidas a hidrólise com diferentes quantidades de sucos de limões Galego, Tahiti ou Cravo.

\begin{tabular}{|c|c|c|c|c|c|c|}
\hline \multirow{3}{*}{$\begin{array}{l}\text { Quantidade de suco de } \\
\text { limão em mL/ } \\
164 \text { mL de solução }\end{array}$} & \multicolumn{6}{|c|}{ Limões } \\
\hline & \multicolumn{2}{|c|}{$\begin{array}{c}\text { Galego } \\
\text { Citrus aurantifolia }\end{array}$} & \multicolumn{2}{|c|}{$\begin{array}{c}\text { Tahiti } \\
\text { Citrus latifolia }\end{array}$} & \multicolumn{2}{|c|}{$\begin{array}{c}\text { Cravo } \\
\text { Citrus limonia }\end{array}$} \\
\hline & $\operatorname{AR}(\%)$ & $\mathrm{pH}$ & $\operatorname{AR}(\%)$ & $\mathrm{pH}$ & $\mathrm{AR}(\%)$ & $\mathrm{pH}$ \\
\hline 1,0 & 4,79 & 3,68 & 6,36 & 3,76 & 3,76 & 3,95 \\
\hline 2,0 & 11,61 & 3,28 & 12,71 & 3,54 & 3,86 & 3,66 \\
\hline 3,0 & 15,37 & 3,03 & 18,76 & 3,26 & 11,25 & 3,47 \\
\hline 5,0 & 22,74 & 2,92 & 32,93 & 3,14 & 14,35 & 3,34 \\
\hline 10,0 & 43,58 & 2,74 & 39,57 & 2,99 & 21,32 & 3,08 \\
\hline 15,0 & 49,60 & 2,66 & 49,27 & 2,85 & 23,30 & 2,93 \\
\hline 20,0 & 54,77 & 2,62 & 52,66 & 2,74 & 35,84 & 2,78 \\
\hline
\end{tabular}

Tabela 3 - Porcentagem da sacarose invertida (açúcares redutores - AR) e ph das soluções aquosas de açúcar em diferentes quantidades do ácido cítrico comercial adicionado em solução aquosa de açúcar cristal (1:1).

\begin{tabular}{ccccccc}
\hline Parâmetros & \multicolumn{5}{c}{ Quantidade de ácido cítrico $(\mathrm{g})$} \\
\cline { 2 - 7 } avaliados & 0,0 & 0,1 & 0,16 & 0,3 & 0,5 & 0,7 \\
\hline AR (\%) & 0,3 & 6,8 & 15,5 & 33,3 & 46,1 & 52,2 \\
pH & 6,72 & 3,42 & 3,37 & 3,13 & 3,06 & 2,65 \\
\hline
\end{tabular}

Para apicultores profissionais/empresariais ou empresariais, ou seja, aqueles com mais de 200 colmeias (Pasin \& Tereso, 2008), este procedimento seria economicamente inviável.

Para verificar a inversão da sacarose por meio do ácido cítrico e do suco de limão das três espécies estudadas, realizaram-se as análises de regressão polinomial, obtendo-se suas respectivas equações (Figura 1). A utilização de soluções mais ácidas para A. mellifera é um fator ainda a ser pesquisado, uma vez que não se conhece qual ou quais seus efeitos nesses insetos.

Para os sucos dos limões Galego e Tahiti, os quais apresentaram porcentagens de inversão próximas, obteve-se uma regressão polinomial (quadrática) dada por: $\mathrm{y}_{\mathrm{Galeco}}=-0,35+5,60$ conc $-0,14$ conc $^{2}\left(\mathrm{R}^{2}=99,4 \%\right)$ (Figura $2 \AA)$ e $\mathrm{y}_{\text {Tahiti }}=3,25+5,42$ conc $-0,15$ conc $^{2}\left(R^{2}=97,0 \%\right)$ (Figura 2B), em que y é a porcentagem de inversão obtida para cada quantidade utilizada (conc). É ainda importante considerar o teor de sacarose (açúcar nãoredutor) presente naturalmente nos sucos dos limões (Tabela 1). Ao se adicionar o suco na solução a ser preparada, está sendo aumentado seu teor de sacarose. Esse aspecto foi constatado quando se utilizou o suco de limão Cravo. Considerando a existência de uma maior concentração de açúcares não-redutores nessa espécie, a inversão foi menor e o ajuste aos dados obtidos foi linear e dado por $\mathrm{y}_{\text {Cravo }}=3,813+1,548$ [conc] $\left(\mathrm{R}^{2}=93,8 \%\right)$ (Figura 2C). Em que concerne à utilização do ácido cítrico comercial para inversão da sacarose em solução aquosa e por meio de uma regressão linear, obteve-se a equação: $\mathrm{y}_{\text {inversão }}=1,128+110,5$ [ácido cítrico] $\left(\mathrm{R}^{2}=93,7 \%\right)$ (Figura 2D).

Os limões Galego e Tahiti têm um teor médio de açúcares não-redutores inferior ao do limão Cravo que é de $2,04 \%$. Desse modo, a partir das equações de regressão estabelecidas, ao se utilizarem $20 \mathrm{~mL}$ de suco de limão, serão obtidas inversões de $55,65 \%$ e pH de 2,52 para o Galego, $51,65 \%$ e pH 2,74 para o Tahiti e somente $34,77 \%$ e pH 2,88 para o limão Cravo. A solução aquosa de açúcar cristal apresentou um pH de 6,72 e com adição de $0,7 \mathrm{~g}$ de ácido cítrico o $\mathrm{pH}$ foi reduzido para 2,65, sendo essa uma solução com maior $\mathrm{pH}$ que a encontrada nos méis brasileiros que segundo Marchini et al. (2004) e Mendonça et al. (2008) é de 3,3 a 4,6, assim como as soluções finais com adição de $20 \mathrm{~mL}$ de suco de limão. Os méis oriundos de colônias provenientes do apiário da UFLA, Lavras-MG, apresentaram pH entre 3,5 e 4,3, encontrando-se próximo à média de 3,9 citada por Crane (1979), obtida para méis oriundos de colônias de abelhas européias em clima temperado. 


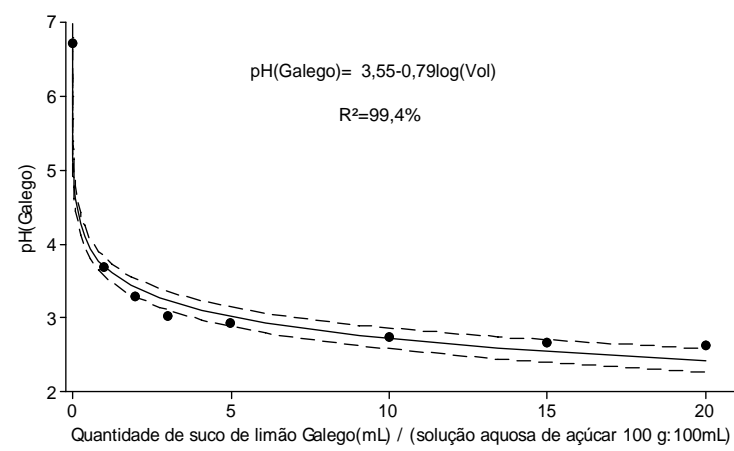

A

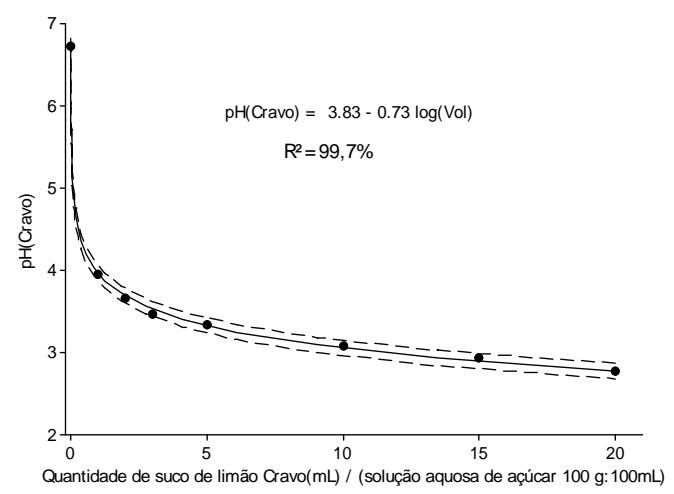

$\mathrm{C}$

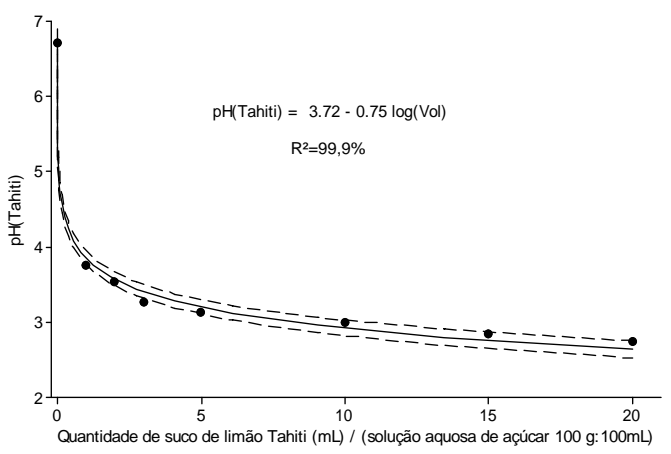

B

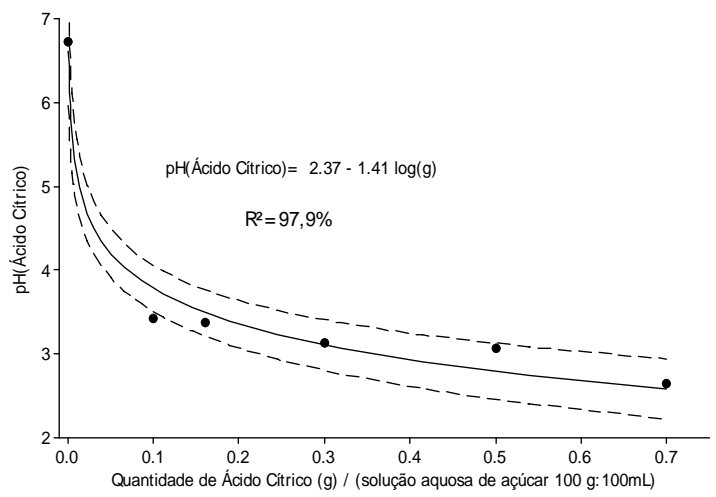

$\mathrm{D}$

Figura 1 - Curvas de regressão ajustadas para o potencial hidrogeniônico da solução aquosa de sacarose em função da adição de sucos de limões (A, B e C) e ácido cítrico (D) e as respectivas regiões de confiança a $95 \%$.

A obtenção e o emprego de uma dieta mais ácida por apicultores em condições de campo poderá provocar distúrbios fisiológicos aos adultos, mudança comportamental, rejeição ao alimento, aumento do volume do abdomem, redução da longevidade, morte prematura dos imagos, interferência na capacidade de vôo, forrageamento, etc. como constatado por Ozcan et al. (2006). Esse ponto deve ser sempre analisado, uma vez que, independente do suco empregado, nas suas maiores concentrações, há uma maior porcentagem de inversão, mas o valor absoluto do $\mathrm{pH}$ é menor.

Desse modo, as quantidades sugeridas de ácido cítrico e suco dos três limões podem ser aquelas que fornecem solução com pH final de 3,3. Nessa condição pode-se também empregar as equações obtidas da análise de regressão (Figura 2) para se determinar com maior precisão as quantidades máximas a serem empregadas quando se deseja fazer a inversão da solução de sacarose, mantendo o $\mathrm{pH}$ mínimo adequado para abelha, baseado na acidez média detectada para méis produzidos no Brasil (Marchini et al., 2004). A partir desse critério pode-se dizer que as quantidades máximas de suco de limão a serem adicionadas em solução composta de $100 \mathrm{~g}$ de açúcar cristal $+100 \mathrm{~mL}$ de água para obtenção de $\mathrm{pH}$ igual a 3,3 e suas respectivas porcentagens de inversão são 2,1 mL (10,7\%), 3,6 mL (21,0\%) e 5,3 mL $(12,1 \%)$ para os limões Galego, Tahiti e Cravo, respectivamente. Para o ácido cítrico a quantidade máxima é de 0,18 g em solução composta de 100 g de açúcar cristal $+100 \mathrm{~mL}$ de água estimando-se uma inversão de 21,0\%. Esse procedimento evitará corrigir o pH da solução final, com a adição de outro composto químico, para uma eventual utilização como alimento para as abelhas. É importante ressaltar que com a utilização de 3,6 mL de suco de limão Tahiti, obtém-se a mesma porcentagem de inversão quando da utilização da quantidade máxima de ácido cítrico, respeitando-se o limite de $\mathrm{pH}$. 


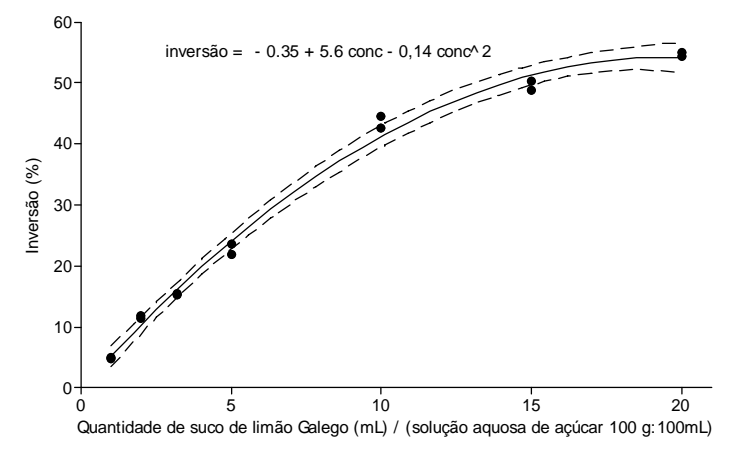

A

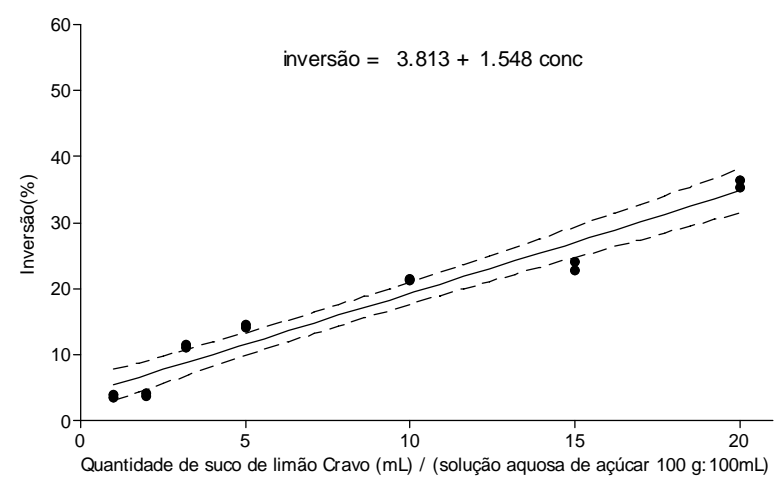

C

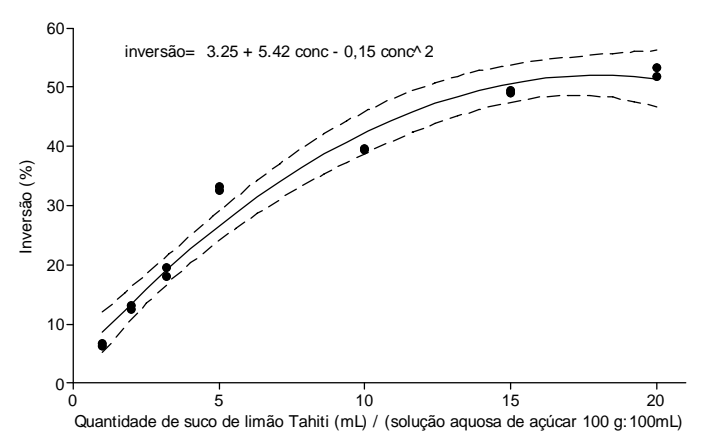

B

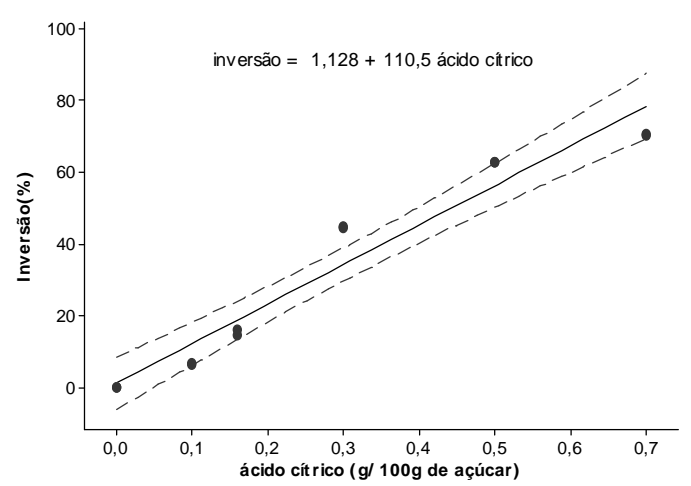

$\mathrm{D}$

Figura 2 - Curva de regressão ajustada e respectiva região de confiança a 95\% para a inversão (\%) do açúcar cristal em solução aquosa em função de quantidades de: A - suco de limão Galego, B - suco de limão Tahiti, C - suco de limão Cravo e D - ácido cítrico.

Outro ponto relevante refere-se à comparação desses resultados com a inversão obtida com a utilização do ácido cítrico. Lengler et al. (2000), conduzindo pesquisas visando ao desenvolvimento de dietas para adultos de A. mellifera, relataram que ao se adicionar $0,1 \mathrm{~g}$ de ácido cítrico em solução aquosa de açúcar cristal (100 mL:100 g), pode-se obter a inversão da sacarose, contudo não mencionaram a porcentagem de inversão obtida. Assim, baseando-se nos resultados da análise de regressão da presente pesquisa e em função do teor de ácido cítrico nas soluções de limões empregados, poderão ser usados 2,$4 ; 1,7$ ou $5,4 \mathrm{~mL}$ de suco dos limões Galego, Tahiti ou Cravo para uma solução aquosa de sacarose (100g de açúcar por $100 \mathrm{~mL}$ de água), obtendo-se proporcionalmente uma inversão de aproximadamente $12,2 \%$ e um $\mathrm{pH}$ de 3,25; 3,54 e 3,30, respectivamente.

De maneira semelhante, Pereira et al. (2006), ao utilizarem $0,16 \mathrm{~g}$ de ácido cítrico para se fazer a inversão da sacarose em solução aquosa de açúcar cristal, não mencionaram qual foi a porcentagem de redução encontrada. Desse modo, considerando os resultados obtidos na análise de regressão do presente ensaio, ao se empregar $0,16 \mathrm{~g}$ de ácido cítrico na inversão da solução de açúcar cristal, foi estimado um desdobramento de $18,8 \%$ e um $\mathrm{pH}$ da ordem de 3,35 . Assim, quando se deseja uma mesma porcentagem de inversão de uma solução de sacarose, poderão ser usados 3,$8 ; 3,2$ ou $9,7 \mathrm{~mL}$ dos sucos dos limões Galego, Tahiti e Cravo e com a obtenção de um pH de 3,09; 3,35 e 3,11, respectivamente. Avaliando esses resultados, nota-se que, ao se utilizar o suco de limão para obter inversão de sacarose equivalente às recomendações de Lengler et al. (2000) e Pereira et al. (2006), o pH estimado fica abaixo do esperado para os casos do limão Galego e Cravo, tornando a solução muito ácida, desse modo, o suco de limão Tahiti seria o mais adequado para substituição do ácido cítrico. 


\section{CONCLUSÕES}

A quantidade máxima de ácido cítrico a ser adicionada em solução aquosa de açúcar cristal (1:1), adotando como critério o potencial hidrogeniônico $(\mathrm{pH})$ dos méis produzidos por abelhas africanizadas, é de $0,18 \mathrm{~g}$ para cada $100 \mathrm{~g}$ de açúcar, obtendo-se uma inversão de $21,0 \%$ da sacarose.

Os sucos dos limões Galego, Tahiti e Cravo podem ser utilizados como substitutos do ácido cítrico para inversão da sacarose na solução aquosa de açúcar cristal (1:1). A quantidade máxima a ser adicionada, respeitandose o limite do $\mathrm{pH}$, corresponde a 2,1; 3,6 e 5,3 mL, para cada $100 \mathrm{~g}$ de açúcar, com porcentagem de inversão de 10,$7 ; 21,0$ e $12,1 \%$, respectivamente.

A porcentagem de inversão e o $\mathrm{pH}$ da solução final, quando se utilizou o suco de limão Tahiti, foram mais próximos daqueles obtidos quando acrescido ácido cítrico comercial.

\section{AGRADECIMENTOS}

Ao Departamento de Ciência de Alimentos da UFLA pelas análises realizadas.

À FAPEMIG pela concessão de bolsa de doutoramento ao primeiro autor.

\section{REFERÊNCIAS BIBLIOGRÁFICAS}

BARKER, R.J.; LEHNER, Y. Laboratory comparison of high fructose corn syrup, grape syrup, honey, and sucrose syrup as maintenance food for caged honey bees. Apidologie, v.9, n.2, p.111-116, 1978.

CRANE, E. Honey: comprehensive survey. London: W. Heinemann, 1979. 680p.

GAYET, J.P.; BLEINROTH, E.W.; NATALLO, M.; GARCIA, E.C.; GARCIA, A.E.; ARDITO, E.F.G.; BORDIN, M.R. Lima ácida Tahiti para exportação: procedimentos de colheita e pós colheita. Brasília: Embrapa, 1995. 36p.

GUY, C.L.; HUBER, J.L.A.; HUBER, S.C. Sucrose phosphate synthase and sucrose accumulation at low temperature. Plant Physiology, v.100, n.1, p.502-508, 1992.

HERBERT JÚNIOR, E.W. Honey bee nutrition. In: GRAHAM, J.M. (Ed.). The hive and the honey bee. Michigan: Dadant \& Sons, 1992. 1324p.

HOLME, D.J.; PECK, H. Analytical biochemistry. Singapore: Longman, 1998. 488p.
LENGLER, S.; KIEFER, C.; ALVES, E.M.; CASTAGNINO, G.L.B. Efeitos da alimentação energética, açúcar invertido e energética-protéica, açúcares e farinha láctea, no desenvolvimento e produção de mel em núcleos de abelhas africanizadas. Mensagem Doce, n.55, p.20-23, 2000.

MARCHINI, L.C.; SODRÉ, G.S.; MORETI, A.C.C.C. Mel brasileiro composição e normas. Ribeirão Preto: A.S. Pinto, 2004. 111p.

MENDONÇA, K.; MARCHINI, L.C.; SOUZA, B.A.; ANACLETO, D.A.; MORETI, A.C.C.C. Caracterização físico-química de amostras de méis produzidos por Apis mellifera L. em fragmento de cerrado no município de Itirapina, São Paulo. Ciência Rural, Santa Maria, v.38, n.6, p.1748-1753, 2008.

MORETI, A.C.de C.C.; SODRÉ, G.da S.; MARCHINI, L.C.; OTSUK, I.P. Características físico-químicas de amostras de méis de Apis mellifera L. do estado do Ceará, Brasil. Ciência e Agrotecnologia, Lavras, v.33, n.1, p.191-199, jan./fev., 2009.

NELSON, N.A. A photometric adaptation of the somogyi method for the determination of glucose. Journal of Biology Chemistry, v.153, n.2, p.375-380, 1944.

OZCAN, M.; ARSLAN, D.; CEYLAN, D.A. Effect of inverted saccharose on some properties of honey. Food Chemistry, London, v.99, n.1, p.24-29, 2006.

PASIN, L.E.V.; TERESO, M.J.A. Análise da infraestrutura existente em unidades de produção agrícola para processamento de mel na região do Vale do ParaíbaSP. Ciência e Agrotecnologia, Lavras, v.32, n.2, p.510516, 2008.

PEREIRA, F.M.; FREITAS, B.M.; VIEIRA NETO, J.M.; LOPES, M.T.R.; BARBOSA, A.L.; CAMARGO, R.C.R. Desenvolvimento de colônias de abelhas com diferentes alimentos protéicos. Pesquisa Agropecuária Brasileira, Brasília, v.41, n.1, p.1-7, 2006.

RODRIGUES, M.V.N.; RODRIGUES, R.A.F.; SERRA, G.E.; ANDRIETTA, S.R.; FRANCO, T.T. Produção de xarope de açúcar invertido obtido por hidrolise heterogênea, através de planejamento experimental. Ciência e Tecnologia de Alimentos, Campinas, v.20, n.1, p.2-15, 2000 . 
SCHMIDT, L.S.; SCHMIDT, J.O.; RAO, H.; WANG, W.; $\mathrm{XU}, \mathrm{L}$. Feeding preference and survival of young worker honey bees (Hymenoptera: Apidae) fed rape, sesame, and sunflower pollen. Journal of Economic Entomology, Amsterdam, v.88, n.6, p.1591-1595, 1995.

SILVA, R.N.; MONTEIRO, V.N.; ALCANFOR, J.X.;

ASSIS, E.M.; ASQUIERI, E.R. Comparação de métodos para a determinação de açúcares redutores e totais em mel. Ciência e Tecnologia de Alimentos, Campinas, v.23, n.3, p.337-341, 2003.

WHITE JÚNIOR, J.W. Composition of honey. In: CRANE, E. Honey: comprehensive survey. London: Heinemann, 1979.

WINSTON, M.L. The biology of the honey bee. London: Harvard University, 1987. 281p. 